\title{
Introduction to Corrosion in Energy Production
}

\author{
RAUL B. REBAK ${ }^{1,2}$ \\ 1.-GE Global Research, 1 Research Circle, CEB2551, Schenectady, NY 12309, USA. 2.-e-mail: \\ rebak@ge.com
}

In some cases, during the production of energy, the environments are very harsh; for example, in the nuclear sector, the materials are in contact with high-temperature coolants under irradiation. In the fossil sector, some hydrocarbons, such as natural gas, have to be obtained from deep wells that are sour and hot. In other sectors, such as in the case of the renewable energy sector, corrosion issues seem to be less pervasive or central to the issue of power generation.

Worldwide, the generation of electric power has several sources of energy that can be grouped as follows: (I) fossil fuels (coal, petroleum and natural gas), (II) nuclear, and (III) renewable (wind, solar, hydroelectric, geothermal, biomass, etc.) sources. ${ }^{1}$

Figure 1 shows that the world energy consumption is still dominated $(>85 \%)$ by the burning of fossil fuels. For fossil fuels, especially in the United States, there is a continuous increase in the use of natural gas and a decrease in the use of coal. ${ }^{2}$ The use of natural gas increased from $15.6 \%$ of the global energy consumption in 1965 to approximately $24 \%$ today. ${ }^{2}$ Many see this as a positive trend in limiting the emission of carbon dioxide $\left(\mathrm{CO}_{2}\right)$ to the environment because natural gas has a lower content of carbon than other fossil fuels. In general, the natural gas used for electrical power generation is highly efficient.

Figure 2 shows the use of energy per supply and per demand in the United States. ${ }^{1}$ For example, liquid fossil fuels represents $36 \%$ of the total energy consumed in the United States; $71 \%$ of the liquid hydrocarbons are used for transportation purposes, which represents $93 \%$ of all the energy used for transportation (Fig. 2). Only $1 \%$ of liquid fuel is used to generate $1 \%$ of the electricity. On the contrary, $91 \%$ of the coal is used to generate $46 \%$ of electricity, and $31 \%$ of the natural gas is used to

Raul B. Rebak, Past Chair and JOM advisor for the Nuclear Materials Committee of the TMS Structural Materials Division (SMD). Dr. Rebak also coordinated the topic Corrosion in Energy Production in this issue. generate $20 \%$ of electric power. Finally, $100 \%$ of the nuclear energy is applied to generating electric power, representing approximately $20 \%$ of the electricity in the United States (Fig. 2).

The subject of corrosion during the process of generation of electricity will be discussed in the four articles presented in this topic. The first article, "High-Temperature Corrosion in Fossil Fuel Power Generation: Present and Future," by Bruce Pint from Oak Ridge National Laboratory, discusses the corrosion issues encountered in the generation of power using coal and natural gas. Dr. Pint discusses the use of coal and natural gas today and a prediction for the near future. In the United States, the use of coal is decreasing, whereas the use of natural gas is constantly increasing. One major problem about the evaluation of materials to be used, for example, in coal-fired plants is that the environments in the field are very difficult to reproduce in the laboratory, both from the fireside and the steam side in the plants.

The second article, "Corrosion in the Oil and Gas Industry: An Increasing Challenge for Materials," by Teresa Perez from Tenaris-Siderca, explores the behavior of materials (mainly steels) to environmental degradation during the production of oil and gas. Much has been learned through more than 60 years of research evaluating the behavior of steels in both sweet (environment controlled by $\mathrm{CO}_{2}$ ) and sour (controlled by $\mathrm{H}_{2} \mathrm{~S}$ ) conditions. Currently, there are rules and standards regarding the limitation in usage of certain materials according to the environment of application. However, as Professor Perez discusses, the basic mechanisms of degradation of steels and the complex interactions among the environment, the mechanical stresses, and the composition and microstructure of the materials are far from being completely understood.

Currently, approximately 30 countries produce electricity using the energy released during nuclear fission. The percentage of electricity generated from nuclear energy varies from country to country. In some countries like France, nuclear electricity represents approximately $75 \%$ (Fig. 3) of the national 


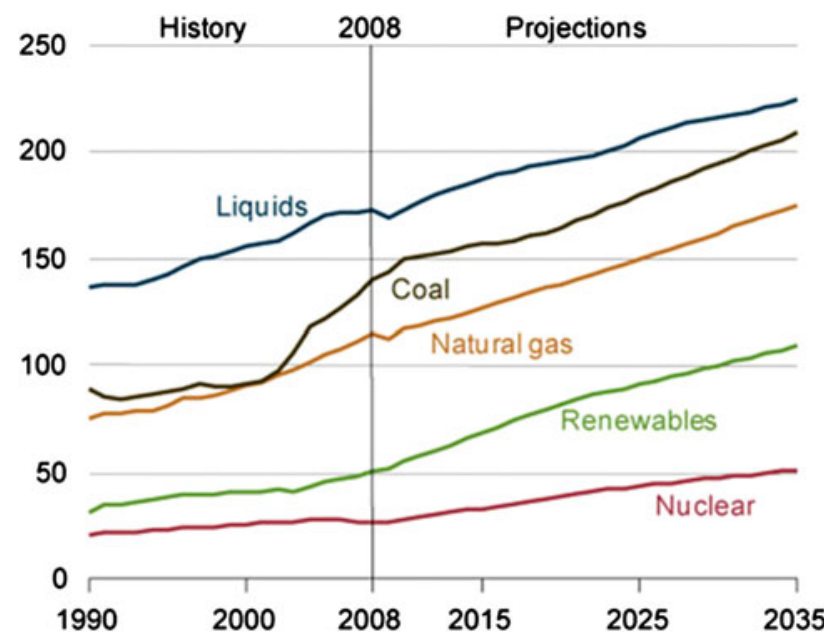

Fig. 1. World energy consumption by fuel 1990-2035 in quadrillion BTU [International Energy Outlook 2011, Report Number: DOE/EIA$0484(2011)]^{1}$

\section{Primary Energy Consumption By Source and Sector, 2011}

\section{quadrillion Btu}

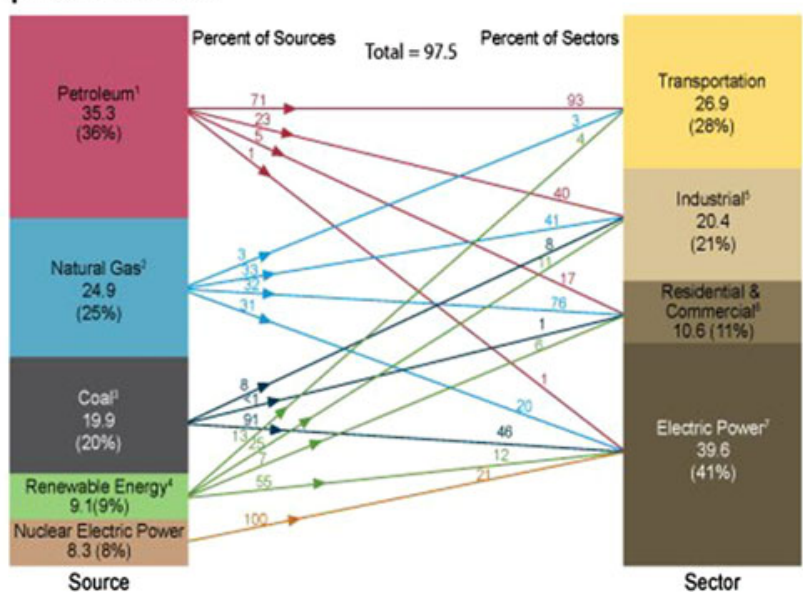

Fig. 2. U.S. energy per supply source and per demand sector in 2011 (DOE Energy Information Administration). ${ }^{1}$

consumption. In the United States, it is approximately $20 \%$, and in other countries like China it is only $2 \% .^{3}$ Figure 4 shows that currently in the world, there are 436 nuclear power reactors producing electricity. The United States has the largest number of reactors (102) in operation, followed by France with 58 reactors, and China with 18 nuclear reactors in operation. Figure 5 shows the number of nuclear reactors connected to the grid annually for the last 50 years. In the mid $1980 \mathrm{~s}$, more than 20 reactors were connected to the grid per year; however, for the last 10 years an average of only $3-4$ reactors was connected annually to the grid. ${ }^{3}$ Due to concerns about climate change, in the early 2000 s, there was a renewed interest in nuclear energy because it does not release greenhouse gases that

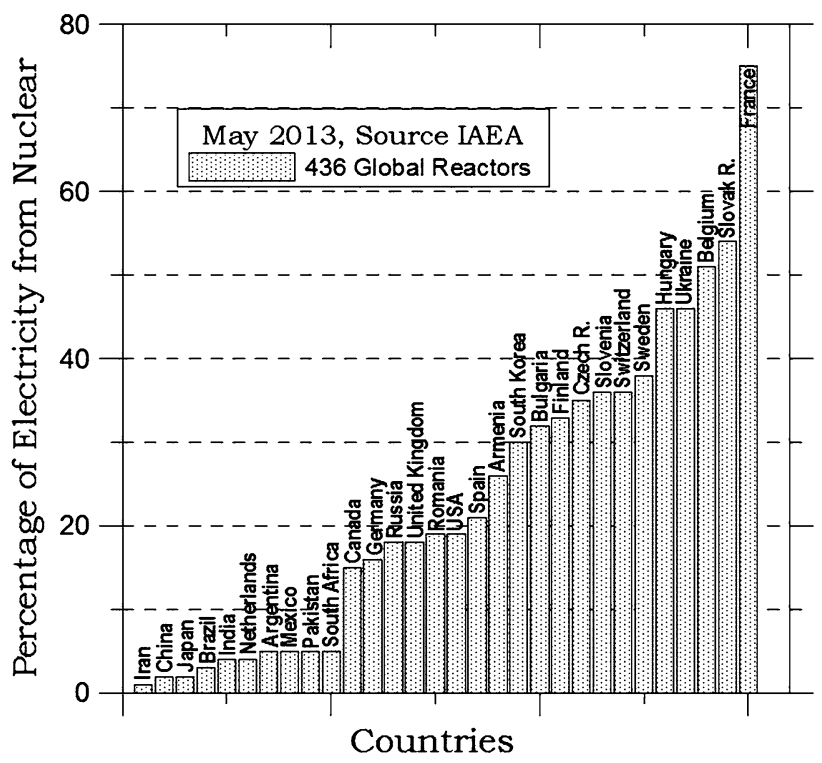

Fig. 3. Percentage of electricity generated using nuclear energy. ${ }^{3}$

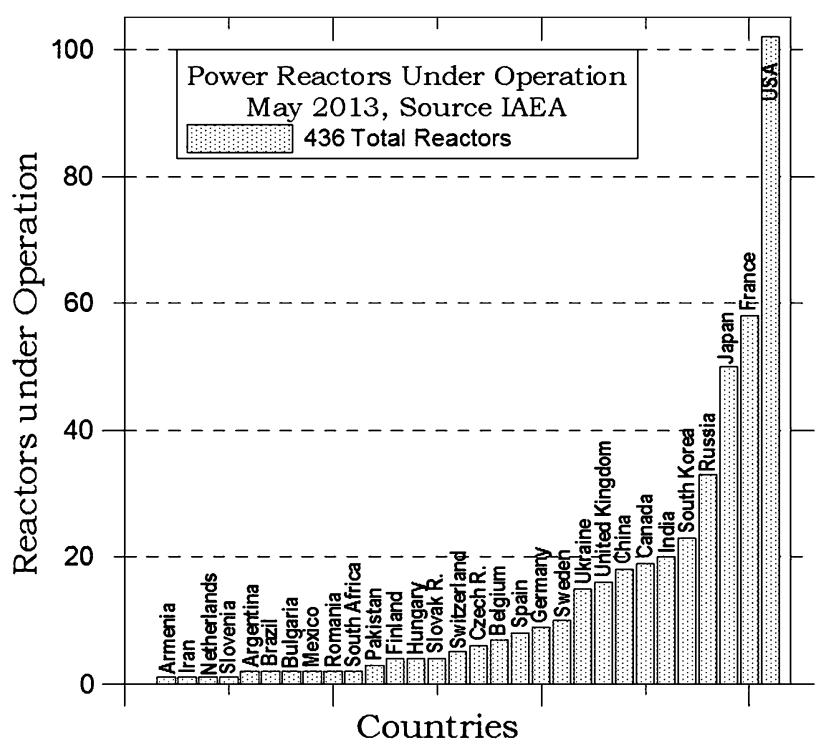

Fig. 4. Nuclear power reactors currently under operation worldwide.

may contribute to global warming. The data of Fig. 5 seem to show that the restored interest in nuclear energy by governments and scientists is not materializing in the commercial sector. It is very expensive and takes a long time (maybe near 10 years) to build a new nuclear reactor plant due to the numerous regulations involved. It is much faster and cheaper to build a power plant fueled by natural gas or coal. Despite the global economic crisis of 2007-2008, the tsunami disaster in northeast Japan in March 2011, and the irrational distrust by the general public, new nuclear power plants are still under construction (Fig. 6). ${ }^{3}$ Most of these newer plants are located in Asia, where the mandates for new plants are mostly controlled by 


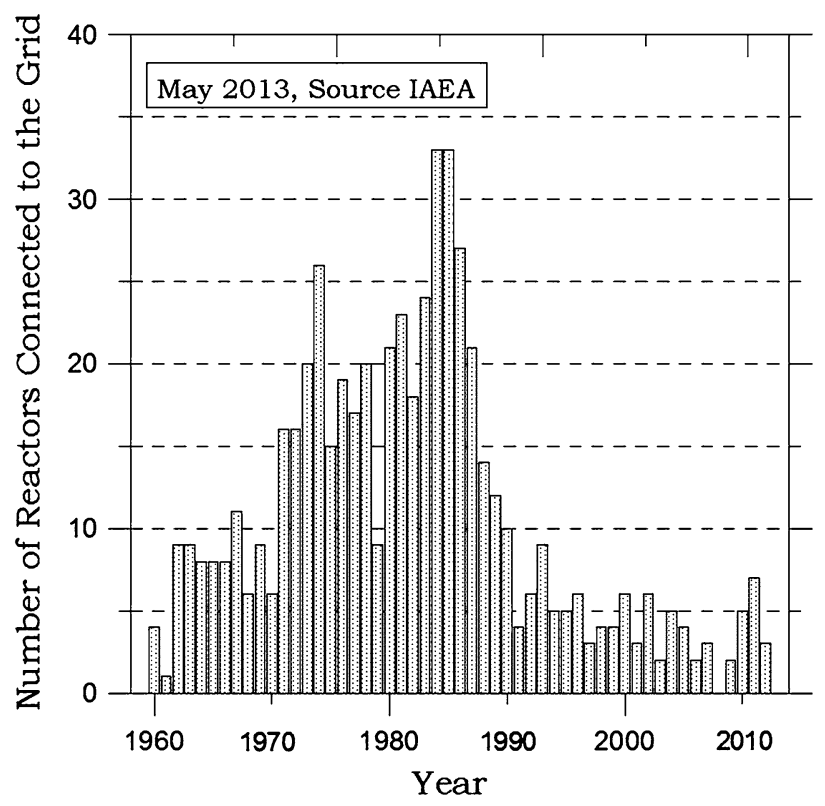

Fig. 5. Nuclear reactors connected to the electrical grid per year.

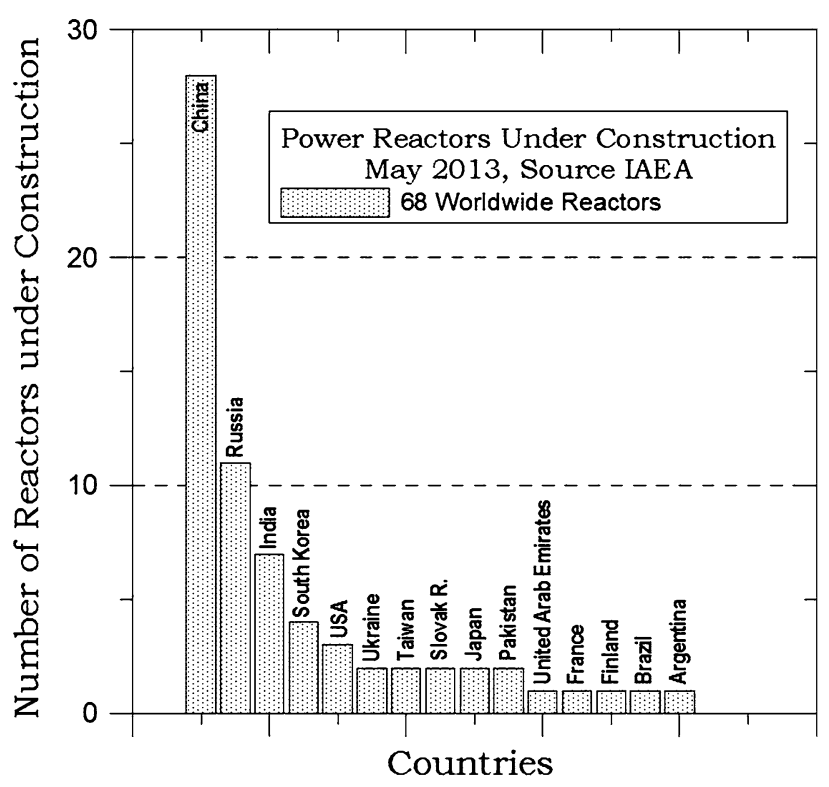

Fig. 6. Nuclear reactors currently under construction. the central governments. The existing 436 nuclear power plants (Fig. 5) and the new plants under construction (Fig. 6) use technology that can be ascribed as up to Generation III. Corrosion problems in these types of plants are described in the third article titled "Corrosion and Corrosion Control in Light Water Reactors" by Barry Gordon from Structural Integrity. The behavior or materials (carbon steel, austenitic stainless steels, and nickelbased alloys) in high-temperature water has been well documented for about five decades, and corrosion engineers seem confident about understanding the behavior of these materials. Most of the plants connected to the grid (Fig. 5) were designed for a lifetime of 40 years. However, many of these plants are requesting and obtaining extensions from regulatory bodies to operate for 60 years and probably for 80 years.

The last article in the series discusses the corrosion behavior of materials for Generation IV type reactors. Specifically, the article "Heavy Liquid Metal Corrosion of Structural Materials in Advanced Nuclear Systems" by Magdalena Caro et al. from Los Alamos National Laboratory, discusses the behavior of materials in molten liquid metal, which is planned to be used as coolant for the near future commercial power plants, especially in Asia. Dr. Caro's contribution is a comprehensive review of the history of material compatibility research in liquid metal environments for nuclear applications with an outstanding listing of references.

In summary, the four following articles address the corrosion behavior of materials in two environmentally demanding sectors of energy generation, namely fossil fuels and nuclear.

\section{REFERENCES}

1. U.S. Department of Energy, Annual Energy Outlook 2013, U.S. Energy Information Administration (EIA), DOE/EIA0383(2013) (Washington, DC: U.S. Department of Energy, 2013).

2. MIT Energy Initiative, MIT Report, The Future of Natural Gas (Cambridge, MA: Massachusetts Institute of Technology, 2011).

3. International Atomic Energy Agency, Power Reactor Information System (PRIS) (Vienna, Austria: International Atomic Energy Agency, 2013). 